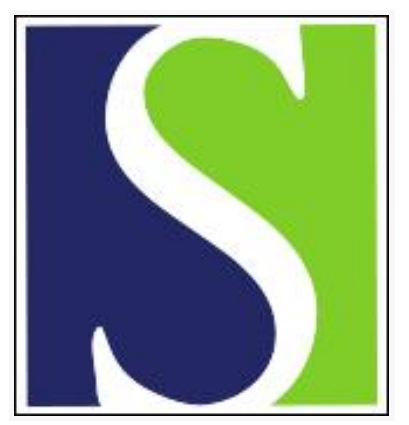

Scand J Work Environ Health 1991;17(6):430-435

https://doi.org/10.5271/sjweh.1684

Issue date: Dec 1991

Monitoring of exposure to cyclohexanone through the analysis of breath and urine.

by Ong CN, Chia SE, Phoon WH, Tan KT, Kok PW

Affiliation: Department of Community Occupational and Family Medicine, National University of Singapore.

This article in PubMed: www.ncbi.nlm.nih.gov/pubmed/1788536

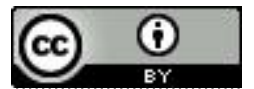




\title{
Monitoring of exposure to cyclohexanone through the analysis of breath and urine
}

\author{
by Choon-Nam Ong, PhD, ${ }^{1}$ Sin-Eng Chia, MSc, ${ }^{1}$ Wai-Hoong Phoon, MFOM, ${ }^{2}$ \\ Kia-Tang Tan, MSc, ${ }^{2}$ Peng-Wai Kok, BSc ${ }^{1}$
}

\begin{abstract}
ONG C-N, CHIA S-E, PHOON W-H, TAN K-T, KOK P-W. Monitoring of exposure to cyclohexanone through the analysis of breath and urine. Scand $J$ Work Environ Health 1991;17:430-5. Occupational exposure to cyclohexanone was studied for 59 workers through the analysis of environmental air, alveolar air, and urinary cyclohexanol. Environmental cyclohexanone exposure was measured by personal sampling with a carbon-felt passive dosimeter. Cyclohexanone in alveolar air and cyclohexanol in urine were determined with gas chromatography with a flame ionization detector. The end-of-shift urinary cyclohexanol levels correlated well with the time-weighted average environmental cyclohexanone values $(r=0.66)$. Urinary cyclohexanol corrected for creatinine correlated best with cyclohexanone in air $(r=0.77)$; when corrected for specific gravity, it gave a similar correlation coefficient $(r=0.73)$. When the time-weighted average of the exposure was $25 \mathrm{ppm}$, the corresponding calculated concentration for urinary cyclohexanol was $54.5 \mathrm{mg} / \mathrm{l}, 23.3 \mathrm{mg} / \mathrm{g}$ of creatinine, or $43.5 \mathrm{mg} / \mathrm{l}$ at a specific gravity of 1.018 . The relationship between cyclohexanone exposure and its concentration in exhaled breath was found to be poorer than that for cyclohexanone exposure and the urinary metabolite $(\mathrm{r}=0.51)$.
\end{abstract}

Key terms: biological monitoring, environmental, occupational exposure, urinary cyclohexanol.

Cyclohexanone is a colorless organic solvent belonging to the group of cyclic ketones. It is a commonly used industrial solvent for cellulose acetate resins, vinyl resins, rubber, and waxes (1). It is also used as a solvent sealer for polyvinyl chloride (PVC) in many medical devices and also in the printing industry (2). In recent years, owing to the widespread use of audio and video equipment, its use has been growing rapidly. Large quantities of cyclohexanone have been used as a coating solvent in audio and video tape production. The current threshold limit value is 25 ppm for cyclohexanone (3).

For guinea pigs, exposure to cyclohexanone was found to produce toxic effects on the hematological and nephrological systems (4). There have been few studies conducted on workers exposed to cyclohexanone. An earlier study suggested that irritation is common at atmospheric concentrations above $50 \mathrm{ppm}$. Exposure to high concentrations can be expected to produce central nervous depression (5).

Although a considerable amount of information on the toxicity of cyclohexanone is available, very little was known about the kinetics and metabolism of the

\footnotetext{
1 Department of Community, Occupational and Family Medicine, National University of Singapore, Singapore.

2 Department of Industrial Health, Ministry of Labour, Singapore.
}

Reprint requests to: Professor CN Ong, Department of Community, Occupational and Family Medicine, National University of Singapore, Singapore 0511. compound until very recently. The main metabolite of cyclohexanone was identified as cyclohexanol (6). In laboratory animals, about 80 to $100 \%$ of the administered dose of cyclohexanone is converted to cyclohexanol and excreted in the urine. Exposure to cyclohexanone can thus be monitored through the measurement of free and conjugated cyclohexanol in the urine.

In a preliminary study of a small group of workers, we demonstrated that the measurement of urinary cyclohexanol can be used for monitoring exposure to cyclohexanone (7). However, so far, no field study has been conducted that compares the amounts of cyclohexanone in exhaled air with the concentration of cyclohexanol in urine.

The American Conference of Governmental Industrial Hygienists recently introduced biological exposure indices to emphasize the importance of using biological indicators in the estimation of occupational risk among workers exposed to industrial solvents (8). The use of biological indicators to evaluate occupational risk must be validated however through the establishment of a close relationship between environmental exposure and biological parameters.

The present study is an extension of two earlier investigations on the environmental and biological monitoring of workers involved with video and audio tape manufacturing $(9,10)$. The objectives of the study were twofold, (i) to determine whether or not it is possible to carry out biological monitoring of workers exposed to this solvent by measuring cyclohexanone in the alveolar air and cyclohexanol in urine and (ii) to evaluate these two noninvasive biological monitoring methods under field conditions. 


\section{Subjects and metiods}

\section{Subjects}

Forty-two production workers from a large video tape manufacturing plant and 17 workers from two plastic bag printing factories in Singapore participated in this study. The ages of the subjects ranged between 18 and 48 years, and the average work experience was 6.3 years. Their average exposure to cyclohexanone was in the range of $1-40 \mathrm{ppm}$. A total of 59 male workers was studied. Twelve of the workers were moderate smokers ( $<40$ cigarettes daily), and six were heavy smokers. Workers with known head, lung, liver, kidney, or any other chronic disease were excluded from the study. None of the workers drank alcohol on a regular basis, and none of them consumed alcohol during the investigation.

Both the environmental and biological monitoring were carried out at midweek. Eight hospital employees who had no occupational history of solvent exposure were used for analytical method evaluations.

\section{Analysis of exhaled breath}

Breath samples were obtained from each worker immediately after his workshift. To minimize the possibility of contamination, the sampling was carried out in a clean area where the mean concentration of cyclohexanone in the air did not exceed $100 \mathrm{ppb}$. Breath sampling was always performed within $10 \mathrm{~min}$ after the worker left the workplace to avoid the very fast washout of organic solvent from the lungs.

The subject was asked to breathe as normally as possible, and then he expired through a sampling tube which was open at both ends (11). Just before the expiration was finished, the tube was closed at both ends, and a portion of the midstream expired air was retained in the tubes; in the present case, it amounted to $300 \mathrm{ml}$. The collection tubes were equipped with perforated screw caps with a rubber disk and teflon membrane that permitted a small volume of air $(100 \mu \mathrm{l})$ to be taken by syi inge for gas chromatography without the tube being opened. The tube was conditioned prior to use by heating to $80^{\circ} \mathrm{C}$ and flushing repeatedly with clean air. Blank tubes were handled in the same way as the sample tubes. The detection limit for cyclohexanone with the described method was $80 \mathrm{ppb}$.

This sampling technique had previously been found to give satisfactory results in our laboratory (9-11). Possible sample loss from tube desorption or from the dissolving of cyclohexanone in breath condensate was not found to be significant. The analysis was conducted immediately after the samples were returned to the laboratory, within $3 \mathrm{~h}$. Generally, the loss was insignificant if the determination was carried out within $5 \mathrm{~h}$ of the collection. Calibration was carried out with a gas-tight quartz cylinder spiked with known concentrations of cyclohexanone. The recovery of cyclohexanone in the range of $0.5-50 \mathrm{ppm}$ was over $84 \%$.
The sampling tubes were kept at $5^{\circ} \mathrm{C}$ during the journey from the factory to the laboratory and then conditioned in an oven at $40^{\circ} \mathrm{C}$ for $30 \mathrm{~min}$ before the analysis. For the analysis, $100 \mu \mathrm{l}$ of air was injected, with a heated gas-tight syringe, into the gas chromatograph.

The concentration of cyclohexanone was measured with a gas chromatograph equipped with a $530 \mu \mathrm{m}$ silicone gum capillary column.

\section{Urine analysis for cyclohexanol}

Urine samples were collected in polycarbonate bottles at the end of the workshift and stored at $-20^{\circ} \mathrm{C}$. The samples were collected in an adjacent building within 30 min after the workers left the factory floor. The analysis was usually performed within $4 \mathrm{~d}$ after the sample collection. It was carried out by adding $0.4 \mathrm{ml}$ of concentrated hydrochloric acid to $2 \mathrm{ml}$ of the urine sample. The mixture was heated for $90 \mathrm{~min}$ at $95^{\circ} \mathrm{C}$. When the mixture had cooled, $0.4 \mathrm{~g}$ of sodium chloride was added. This step was followed by the extraction of the sample with $2 \mathrm{ml}$ of diethyl ether in a separating funnel, and the procedure was repeated. The detailed procedures have been described earlier (7).

The detection limit for urinary cyclohexanol with the present method was $0.4 \mathrm{mg} / 1$. The results were presented as observed $(\mathrm{mg} / \mathrm{l})$ or after correction for the creatinine concentration (mg/g creatinine) or for specific gravity at 1.018 . The specific gravity was measured by refractometry, and the creatinine by an $\mathrm{Ab}$ bott autoanalyzer with a procedure based on Jaffe's method.

\section{Standards preparation/calibration}

Standard solutions were prepared with various amounts of cyclohexanol and analyzed by the aforementioned extraction procedure using the standards addition method. The final concentration of cyclohexanol ranged from 0.5 to $100 \mathrm{mg} / \mathrm{l}$. Cycloheptanol was used as an internal standard. Using the internal standard helped to reduce variability and improve accuracy. Nevertheless, later, the internal standard was found not to be essential, as cyclohexanol is not a normal metabolite in urine and the calibration graph using the standards addition method was linear.

The lowest detection limit with the aforementioned method with a flame ionization detector was $0.4 \mathrm{mg} / 1$ with a sample size of $2 \mu \mathrm{l}$ for gas chromatograph determination. Cyclohexanol was not detected in the urine of the eight unexposed hospital staff. In the present study all the urinary cyclohexanol determinations were carried out within $4 \mathrm{~d}$ of the urine collection.

\section{Environmental sampling}

Individual exposure to cyclohexanone at the workplace was monitored with an organic vapor monitor (model 3500 , Minnesota Mining and Manufacturing) through- 
out the whole workshift of $8 \mathrm{~h}$, from 0700 to 1500 . The passive dosimeters were attached to the collar or shirt pocket of the workers before they entered the plant. Organic solvent vapors then diffused through the bed of absorbent (activated carbon wafer) in the monitor. Dosimeters were detached at the end of the shift and stored at $-4^{\circ} \mathrm{C}$ until the analysis. The col-
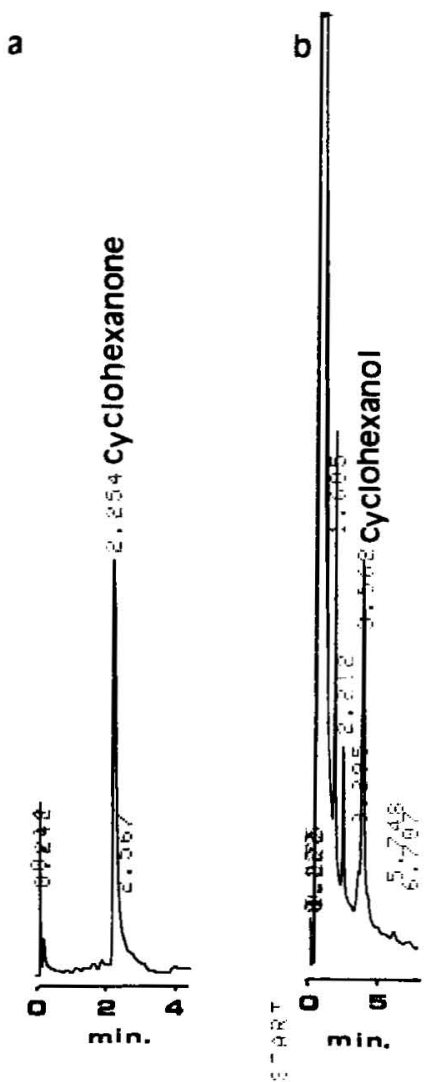

Figure 1. Gas chromatographic determination of cyclohexanone in exhaled air (a) and cyclohexanol in urine (b) from a worker from the mixing department of the video tape production plant.

Table 1. Gas chromatographic conditions for environmental and breath cyclohexanone and urinary cyclohexanol determined with a Hewlett Packard 5890A gas chromatograph with a flame ionizing detector and a Shimadzu CR-3 A integrator

\begin{tabular}{llll}
\hline & \multicolumn{3}{c}{ Temperature } \\
\cline { 2 - 4 } & $\begin{array}{l}\text { Environmental } \\
\text { cyclohexanone }\end{array}$ & $\begin{array}{l}\text { Breath } \\
\text { cyclohexanone }\end{array}$ & $\begin{array}{l}\text { Urinary } \\
\text { cyclohexanol }\end{array}$ \\
\cline { 2 - 4 } Injector & $100^{\circ} \mathrm{C}$ & $130^{\circ} \mathrm{C}$ & $150^{\circ} \mathrm{C}$ \\
Detector & $200^{\circ} \mathrm{C}$ & $200^{\circ} \mathrm{C}$ & $200^{\circ} \mathrm{C}$ \\
Column & $35^{\circ} \mathrm{C} \times 1.5 \mathrm{~min}$ & $45^{\circ} \mathrm{C} \times 0.8 \mathrm{~min}$ & $60^{\circ} \mathrm{C} \times 2 \mathrm{~min}$ \\
& $25^{\circ} \mathrm{C} / \mathrm{min}$ & $35^{\circ} \mathrm{C} / \mathrm{min}$ & $10^{\circ} \mathrm{C} / \mathrm{min}$ \\
& $80^{\circ} \mathrm{C} \times 1.5 \mathrm{~min}$ & $80^{\circ} \mathrm{C} \times 5 \mathrm{~min}$ & $70^{\circ} \mathrm{C} \times 5 \mathrm{~min}$ \\
& $70^{\circ} \mathrm{C} / \mathrm{min}$ & $70^{\circ} \mathrm{C} / \mathrm{min}$ & $70^{\circ} \mathrm{C} / \mathrm{min}$ \\
& $120^{\circ} \mathrm{C} \times 2 \mathrm{~min}$ & $120^{\circ} \mathrm{C} \times 1.5 \mathrm{~min}$ & $120^{\circ} \mathrm{C} \times 2 \mathrm{~min}$ \\
\hline
\end{tabular}

a $10 \mathrm{~m} \times 530 \mu \mathrm{m} \mathrm{ID}, 2.65 \mu \mathrm{m}$ film thickness HP-1, methyl sili. cone gum capillary column. lected sample was removed from the activated carbon wafer by desorption with $1.5 \mathrm{ml}$ of carbon disulfide. The amount of cyclohexanone in the dosimeter was determined within one week. An autosampler was used, together with an integrator, for the gas chromatographic determination of cyclohexanone. The injection volume was $2 \mu \mathrm{l}$.

\section{Gas chromatographic conditions}

The gas chromatographic conditions for the analysis of the biological and environmental samples are shown in table 1. Internal quality control was carried out by spiking urine samples obtained from hospital staff who were not occupationally exposed to any organic solvents with known concentrations of cyclohexanol. The within-run coefficient of variation for urinary cyclohexanol was $5.4 \%$, and the day-to-day coefficient of variation was $9.7 \%$. Typical chromatograms of cyclohexanone in exhaled air and cyclohexanol in urine are shown in figure 1 ( $a$ and $b$, respectively). The peak for cyclohexanone in exhaled air appeared about $2.5 \mathrm{~min}$ after the injection, with no interference with other components in the breath. Cyclohexanol in urine took a slightly longer time for analysis; the peak appeared at about 3.5 min under the analytical conditions described in table 1 .

\section{Results}

For the video tape production plant, the production process involved mixing iron oxide and coating polythene film with it, and cyclohexanone was one of the main solvents used. Preliminary environmental monitoring indicated that, in the mixing and coating departments, the concentrations varied throughout the workshift, the cyclohexanone level occasionally reaching a time-weighted average of $40 \mathrm{ppm}$. Workers in the calendering, slitting, and packaging departments were generally exposed to relatively steady levels of cyclohexanone. The time-weighted average concentrations in these three sections were about 20,10 and $2 \mathrm{ppm}$, respectively.

In the plants printing plastic bags, cyclohexanone was used as the main solvent for the printing ink; toluene was used occasionally. The time-weighted average concentration of cyclohexanone was generally lower, in the range of 0.5 to $10 \mathrm{ppm}$.

The environmental cyclohexanone concentrations and the various biological measurements are summarized in table 2 .

Figure 2 shows the correlation between the cyclohexanone concentrations in the breathing samples and the time-weighted average concentrations of the environmental cyclohexanone. The linear correlation coefficient (r) was $0.51(\mathrm{P}<0.01)$.

Figure 3 shows the correlations between urinary cyclohexanol and the time-weighted environmental cyclohexanone concentrations. The correlation coeffi- 
cients were $0.66,0.73$, and 0.77 for the uncorrected urine samples, the samples corrected for specific gravity at 1.018 , and samples corrected for urinary creatinine, respectively. It was noted that the corrections for specific gravity and urinary creatinine improved the correlation coefficients with the concentrations of cyclohexanone collected from the breathing zone.

Table 3 summarizes the relationships between environmental cyclohexanone, exhaled air concentrations, and urinary cyclohexanol measured at the end of the workshift. The breath cyclohexanone concentration did not appear to have any close association with the urinary cyclohexanol concentrations.

\section{Discussion}

The objective of studying biological exposure indices is to estimate the relationship between exposure and biological responses so that a biological standard corresponding to exposure can be established. In the present study, two noninvasive biological monitoring methods using exhaled air and the measurement of metabolite in urine were evaluated for occupational exposure to cyclohexanone.

\section{Cyclohexanone in exhaled breath}

The analysis of exhaled breath is becoming increasingly popular as a biological monitoring method. The technique has recently been brought into prominence by its incorporation into the biological exposure indices of threshold limit values (8). An extensive review of the procedures, applications, and limitations of breath sampling was recently presented in the literature (12). This approach offers a noninvasive way to estimate the uptake of solvents through inhalation. Although much work has been undertaken on the use of this technique for biological monitoring under controlled conditions in exposure chambers or laboratory conditions, relatively few data are available from field studies.

In the present field investigation, the average environmental exposure to cyclohexanone was $9.04 \mathrm{ppm}$ with only a few of the workers exposed to levels above 25 ppm. The data show that breath cyclohexanone is proportional to a cyclohexanone concentration of $1-40 \mathrm{ppm}$ in breathing zone air. The scatter plot, however, shows large individual variation (figure 2). Calculations based on an exposure of 9 ppm would be expected to produce a breath concentration of around $1 \mathrm{ppm}$ at the end of the workshift.

The analysis of exhaled breath is noninvasive and is thus more acceptable to workers than blood sampling. Through measurements of exhaled breath at the end of exposure, it is theoretically possible to estimate the amount of material that is present in the body (12). However, the main setback for breath analysis is that the results can vary considerably, depending on the type of sampling technique and the time of sampling. Breath analysis reflects the uptake accurately provided that the exposure was relatively constant over the work period, but in field situations the exposure usually varies throughout the day (12). There are several other factors that may also affect breath analysis - the solubility of the solvent in blood, metabolic clearance, cigarette smoking, absorption from other routes, and the vital capacity of the lung $(12,13)$.

One major disadvantage of breath analysis is that samples have to be analyzed soon after collection, as storage leads to significant loss $(11,13)$. Therefore, the use of this technique has not been found to be satisfactory in some studies $(14,15)$. It is also necessary to mention that, when using exhaled breath for biological monitoring, we have to consider the very fast washout of organic solvent from the lungs. Thus far, the half-time of cyclohexanone in lungs has not been

Table 2. Mean concentrations and ranges of the various parameters measured. ( $\mathrm{sg}=$ corrected for specific gravity at $1.018, \mathrm{cr}=$ corrected for urinary creatinine)

\begin{tabular}{lcrc}
\hline Parameter & Mean & SD & Range \\
\hline $\begin{array}{l}\text { Environmental cyclo- } \\
\text { hexanone (ppm) }\end{array}$ & 9.04 & 9.5 & $0.1-36.0$ \\
$\begin{array}{l}\text { Breath cyclohexanone (ppm) } \\
\text { Urinary cyclohexanol (mg/l) }\end{array}$ & 1.08 & 1.2 & $0-6.4$ \\
$\begin{array}{l}\text { Urinary cyclohexanol } \\
\text { (mg }\end{array}$ & 15.3 & 13.9 & $0.4-66.2$ \\
$\begin{array}{l}\text { Urinary cyclohexanol } \\
\text { (mg/g cr) }\end{array}$ & 13.7 & 12.7 & $1.5-65.2$ \\
\hline
\end{tabular}

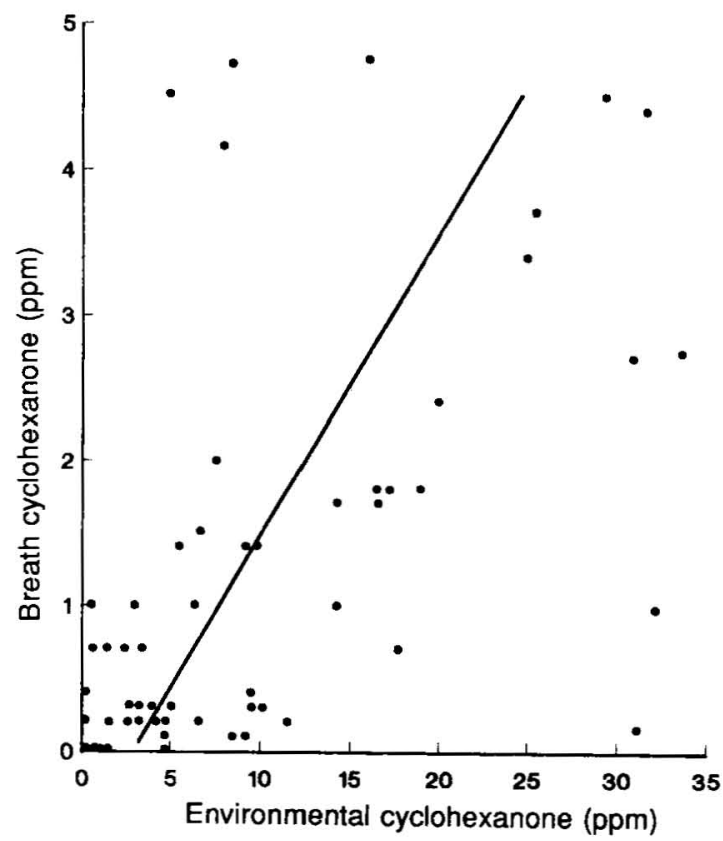

Figure 2. Relation between cyclohexanone in exhaled breath and the time-weighted average concentrations of cyclohexanone collected from the breathing zone. Points indicate individual values $(Y=-1.27+0.26 x$, Pearson's correlation coefficient, $r=0.51$ ) 

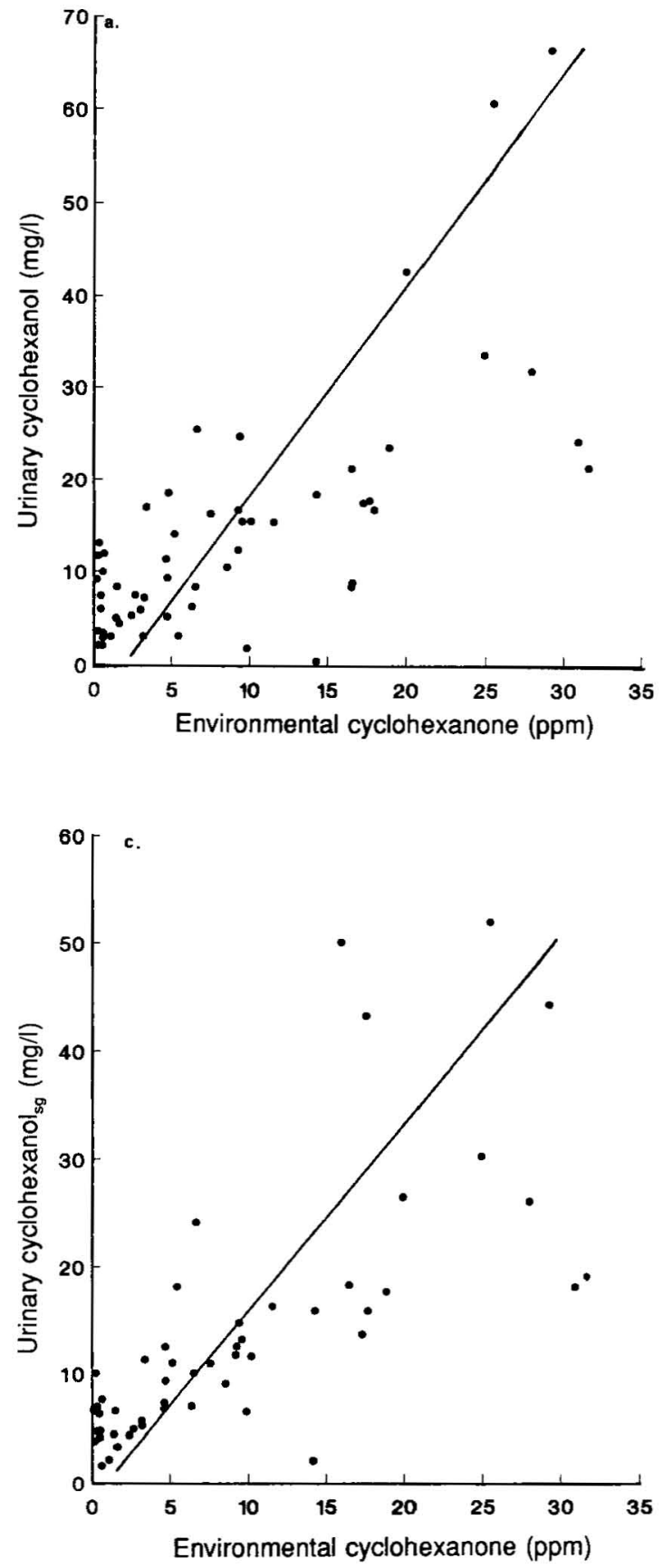

Table 3. Correlations between environmental exposure, breath cyclohexanone, and urinary cyclohexanol $(\mathrm{N}=59)$. ( $\mathrm{sg}=$ corrected for specific gravity at $1.018, \mathrm{cr}=$ corrected for urinary creatinine)

\begin{tabular}{lcccc}
\hline & $\begin{array}{c}\text { Breath } \\
\text { cyclo- } \\
\text { hexanone }\end{array}$ & $\begin{array}{c}\text { Urinary } \\
\text { cyclo- } \\
\text { hexanol }\end{array}$ & $\begin{array}{c}\text { Urinary } \\
\text { cyclo- } \\
\text { hexanol }\end{array}$ & $\begin{array}{c}\text { Urinary } \\
\text { cyclo- } \\
\text { hexanol }\end{array}$ \\
\cline { 2 - 5 } & & & & \\
$\begin{array}{l}\text { Environmental } \\
\text { cyclohexanone }\end{array}$ & 0.51 & 0.66 & 0.77 & 0.73 \\
$\begin{array}{l}\text { Breath } \\
\text { cyclohexanone }\end{array}$ &. & 0.34 & 0.42 & 0.50 \\
\hline
\end{tabular}

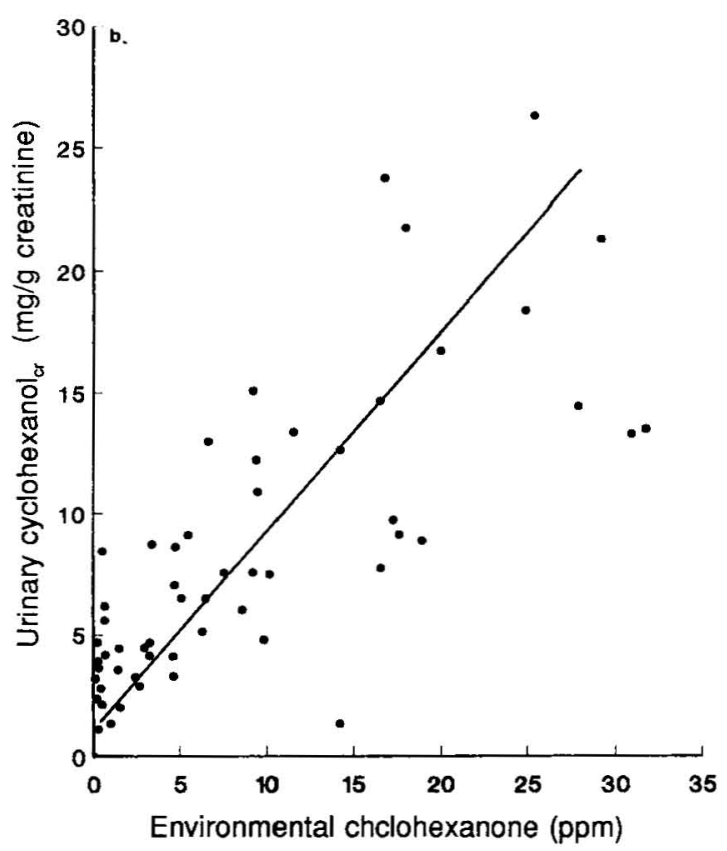

Figure 3. Relation between breathing zone air and unadjusted urinary cyclohexanol collected at the end of the workshift. ( $\mathrm{a}=$ unadjusted urinary values, $\mathrm{Y}=-10.45+2.23 \mathrm{X}, \mathrm{r}=0.66$; $b=$ urinary values adjusted for creatinine (cr), $Y=-0.42+$ $0.95 \mathrm{X}, \mathrm{r}=0.77 ; \mathrm{c}=$ urinary values adjusted for specific gravity (sg), $Y=-3.75+1.89 X, r=0.73$ )

determined. However, a significant drop of $20 \%$ was noted if samples were collected $30 \mathrm{~min}$ after the workers left their workplace. In order to avoid this problem, we collected exhaled air within $10 \mathrm{~min}$ of the end of the workshift.

The correlation coefficient of 0.51 for breath cyclohexanone and environmental exposure was found to be less representative when compared with the results of our earlier studies using the same procedures on toluene $(r=0.90)(11)$, but closer to the value for 
methyl ethyl ketone $(r=0.47)(16)$. It appears that the accuracy of using breath analysis also depends on the solvent studied. It has recently been pointed out that exhaled air monitoring is not suitable for chemicals highly soluble in water, such as ketones, but it is more acceptable for solvents like trichloroethylene and perchloroethane (17). Thus it is not surprising that some authors may have found breath analyses unsatisfactory for certain solvents, and others have used it successfully for different volatile compounds.

\section{Urine analysis for cyclohexanol}

The scattergrams in figure 3 show that the urinary cyclohexanol concentrations correlated well with the time-weighted average concentration of cyclohexanone at the workplace. The results also showed that urinary cyclohexanol corrected for creatinine correlated best with the environmental cyclohexanone exposure. Furthermore, the creatinine-corrected urinary cyclohexanol also showed a statistically significant association $(r=0.5)(P<0.01)$ with the breath cyclohexanone concentration (table 3 ).

The analysis for urinary cyclohexanol is relatively easy and specific. In addition, this metabolite of cyclohexanone is not usually present in the urine and thus is reliable for the screening of exposure. The method used in the present investigation for determining cyclohexanol in urine is sensitive. In the present case, it was specific enough to detect cyclohexanol in urine for those who were exposed to cyclohexanone well below the current exposure limit of 25 ppm (3). A laboratory study on animals revealed that over $80 \%$ of the cyclohexanone administered was converted to cyclohexanol and excreted in urine (6). Therefore, it is not surprising that a fairly large quantity of cyclohexanol was excreted in our occupationally exposed group.

In consideration of the good correlation between the postshift urinary cyclohexanol level and environmental exposure, measuring the urinary concentration of cyclohexanol appears to be the method of choice.

At an exposure of $25 \mathrm{ppm}$, the corresponding calculated concentration for urinary cyclohexanol was $54.5 \mathrm{mg} / 1$ (43.5 mg/1 adjusted for specific gravity at 1.018 and $23.3 \mathrm{mg} / \mathrm{g}$ for urine corrected with creatinine concentration). No attempt was made in the present study to estimate the biological half-time of cyclohexanone. In a follow-up study on five of the subjects very little cyclohexanol was detected in urine collected the next morning. Our recent study on the kinetics of a similar compound of the ketone family, methyl ethyl ketone, also suggested that the ketone concentration rose steadily until the end of exposure (16). These findings suggest that the measurement of urinary cyclohexanol at the end of the workshift is appropriate for exposure measurements.

\section{Acknowledgments}

This work was supported in part by Singapore Turf Club Grant number 5712.

We thank Ms GL Sia and Mr HY Ong for their technical assistance.

\section{References}

1. Gupta PK, Lawrence WH, Turner JE, Autein J. Toxicological aspects of cyclohexanone. Toxicol Appl Pharmacol 1985;49: 525-33.

2. Ulsaker GA, Korsnes RM. Determination of cyclohexanone in intravenous solutions stored in PVC bags by gas chromatography. Analyst 1980;102:882-3.

3. American Conference of Governmental Industrial Hygienists (ACGIH). Threshold limit values and biological exposure indices for 1990. Cincinnati, OH: ACGIH, 1990.

4. James SP, Waring RH. The metabolism of alicyclic ketones with rabbit and rat. Xenobiotica 1983;1:573-80.

5. Smith HF, Carpenter CP, Weil CS. Range finding toxicity data VII. Am Ind Hyg Assoc J 1969;30:470-6.

6. Martis L, Tolhurst T, Koeferl MT, et al. Disposition kinetics of cyclohexanone in beagle dogs. Toxicol Appl Pharmacol 1980;55:545-53.

7. Ong CN, Sia GL, Chia SE, Phoon WH, Tan KT. Determination of cyclohexanol in the urine and its use in environmental monitoring of cyclohexanone exposure. J Anal Toxicol 1991;15:13-6.

8. American Conference of Governmental Industrial Hygienists (ACGIH). Documentation of the threshold limit values and biological exposure indices. 5th edition. Cincinnati, $\mathrm{OH}$ : ACGIH, 1986.

9. Ong CN, Chia SE, Phoon WH, Tan KT. Biological monitoring of occupational exposure to tetrahydrofuran. $\mathrm{Br} \mathrm{J}$ Ind Med 1991;48:616-21.

10. Sia GL, Ong CN, Chia SE, Phoon WH, Tan KT. Biological and environmental monitoring of methyl ethyl ketone (MEK). Environ Monitor Assess 1991;16:27081.

11. Foo SC, Jeyaratnam J, Ong $\mathrm{CN}$, et al. Biological monitoring for exposure to toluene. J Am Ind Hyg Assoc 1991;45:283-91.

12. Droz PO, Guillemin MP. Occupational exposure using breath analysis. J Occup Med 1986;28:593-602.

13. Campbell L, Marsh DM, Wilson HK. Towards a biological monitoring strategy for toluene. Ann Occup Hyg 1987;31:121-33.

14. Money CD, Gray CN. Exhaled breath analysis as a measure of workplace exposure to benzene. Ann Occup Hyg 1989;33:257-62.

15. Perbellini L, Faccini GB, Passini F, et al. Environmental and occupational exposure to benzene by analysis of breath and blood. Br J Ind Med 1988;45:345-52.

16. Ong CN, Sia GL, Ong HY, Phoon WH, Tan KT. Biological monitoring of occupational exposure to methyl ethyl ketone. Int Arch Environ Occup Health (in press).

17. Rosenberg J, Fiserova-Bergerova V, Lowry LK. Biological monitoring IV: measurements in urine. Appl Ind Hyg 1989;4:16-20.

Received for publication: 19 April 1991 